\title{
Characterization of Nanosilver Biosynthesis by Citrus sinensis (L.) Osbeck and Peel-off Mask Formulation with Variation Polyethylene Glycol 400-Glycerin Concentration
}

\author{
Dian E. Ermawati*, Agung P. Surya, Adi Yugatama \\ Department of Pharmacy, Mathematics and Natural Science Faculty, Universitas Sebelas Maret, Jalan Ir. Sutami 36 A \\ Kentingan, Jebres, Surakarta 57126
}

Submitted 15 October 2020; Revised 8 December 2021; Accepted 11 December 2021; Published 30 December 2021

*Corresponding author: dianekae@staff.uns.ac.id

\begin{abstract}
Sweet orange contains flavonoids and citric acid that have the potential as a capping agent in the nanosilver biosynthesis process. The antibacterial activity of silver can be increased in nanoparticles, then it can be applied to treat acne through a peel-off mask preparation. Glycerin and Polyethylene glycol 400 are humectants that combined to obtain good physicochemical properties of the preparation. This study aims to determine the character of nanosilver biosynthesis and the effect of humectant combination on the physicochemical properties of the preparation. The characterization of nanosilver was employed by UV-VIS Spectrophotometry, Particle Size Analysis, and Scanning Electron Microscope. The GlycerinPEG 400 combination was F1 (0:100\%); F2 (25:75\%); F3 (50:50\%); F4 (75:25\%) and F5 (100:0\%). The results of nanosilver biosynthesis have an absorption peak of nanoparticles at $421-423 \mathrm{~nm}$, rod shape, the particle size of $83.2 \pm 7.2 \mathrm{~nm}$. Statistical analysis showed that the combination of GlycerinPEG 400 had a significant effect on organoleptic, viscosity, and dry time, but did not affect the $\mathrm{pH}$ of preparation. The combination of Glycerin-PEG 400 (75\%:25\%) is the best formula because it has stable viscosity, dry time, and $\mathrm{pH}$ value during storage for four weeks.
\end{abstract}

Keywords: nanosilver, biosynthesis, Citrus sinensis, humectants, peel off mask

\section{Karakterisasi Perak Nanopartikel Hasil Biosintesis Infusa Kulit Jeruk (Citrus sinensis (L.) Osbeck) dan Formulasi Sediaan Masker Peel-off dengan Variasi Konsentrasi Gliserin-Polietilen Glikol 400}

\begin{abstract}
Abstrak
Jeruk manis mengandung flavonoid dan asam sitrat yang berpotensi sebagai bioreduktor dan capping agent pada biosintesis perak nanopartikel. Aktivitas antibakteri perak dapat ditingkatkan dalam ukuran nano, selanjutnya dapat diaplikasikan untuk perawatan kulit berjerawat melalui sediaan masker peeloff. Gliserin dan PEG 400 adalah humektan yang akan dikombinasikan untuk mendapatkan sifat fisikakima sediaan yang baik. Penelitian ini bertujuan untuk mengetahui karakter perak nanopartikel hasil biosintesis, dan pengaruh kombinasi humektan terhadap sifat fisik-kimia sediaan masker peel-off. Karakterisasi perak nanopartikel dilakukan dengan Spektrofotometri UV-VIS, Particle Size Analysis, dan Scanning Electron Microscope. Kombinasi Gliserin-PEG 400 yaitu F1 (0:100\%); F2 (25\%:75\%); F3 (50\%:50\%); F4 (75\%:25\%) and F5 (100\%:0). Hasil biosintesis menghasilkan perak nanopartikel dengan serapan maksimal khas nanopartikel pada 421-423 nm, bentuk morfologi batang berukuran $83,17 \pm 7,19 \mathrm{~nm}$. Analisa statistika menunjukan kombinasi Gliserin-PEG 400 berpengaruh signifikan terhadap sifat organoleptis, viskositas, dan waktu kering sediaan, namun tidak berpengaruh pada $\mathrm{pH}$. Kombinasi Gliserin-PEG 400 (75\%:25\%) merupakan formula terpilih karena memiliki nilai viskositas, waktu kering, dan $\mathrm{pH}$ yang stabil selama penyimpanan empat minggu pada suhu ruang.

Kata Kunci: perak nanopartikel, biosintesis, Citrus sinensis, humektan, masker peel-off
\end{abstract}




\section{Introduction}

Timbulnya jerawat ditandai adanya flora normal kulit seperti Straphylococcus aureus dan Straphylococcus epidermidis pada komedo. ${ }^{1}$ Penggunaan antibiotik topikal seperti Clindamycin dan Eritromycin untuk mengatasi jerawat, dalam jangka panjang dapat memicu perkembangan resistensi bakteri. ${ }^{2}$ Untuk mengatasi hal tersebut perlu dikembangkan agen antibakteri yang aman digunakan salah satunya perak nanopartikel. Perak digunakan sebagai antiseptik dan menunjukan aktivitas biosidal dengan spektrum yang luas. ${ }^{3}$ Dengan dibuat ukuran nano, aktivitasnya akan meningkat sebagai antibakteri serta dapat meningkatkan stabilitas jika digunakan sebagai bahan aktif dalam formula kosmetik. ${ }^{4}$ Nilai konsentrasi efektif minimal perak nanopartikel dalam sediaan kosmetik yaitu setara dengan $10 \mathrm{mg} /$ Kg. ${ }^{5}$ Nanopartikel yang memiliki ukuran 20$200 \mathrm{~nm}$ hanya mampu menembus stratum korneum sejauh 2-3 $\mu \mathrm{m}$ saja (stratum korneum merupakan lapisan terluar kulit dengan ukuran 15-20 $\mu \mathrm{m}$ ) sehingga perak nanopartikel tidak masuk ke dalam saluran sistemik. Science Committee on Consumer Safety (SCCS) membatasi paparan perak pada tubuh tidak boleh melebih 10.000 ppm. $^{6}$

Pembuatan perak nanopartikel dapat dilakukan dengan metode fisika dan kimia yang biasanya berisiko dan menghasilkan limbah yang merugikan lingkungan. Ekstrak tanaman dikembangkan sebagai agen biosintesis perak dengan pertimbangan lebih aman, sederhana dan tidak menghasilkan limbah berbahaya bagi lingkungan. Infusa kulit jeruk manis (Citrus sinensis) dapat dimanfaatkan sebagai capping agent dalam pembentukan perak nanopartikel dan terbukti memiliki aktivitas antibakteri spektrum luas dengan ukuran partikel antara $10-35 \mathrm{~nm} .{ }^{3}$ Kulit jeruk manis ( C. sinensis) menghasilkan ukuran partikel perak yang terkecil dibandingkan dengan tumbuhan segenus seperti lemon $(C$. limon) dan jeruk nipis manis (C.limetta), dimana masing-masing menghasilkan perak nanopartikel dengan ukuran 17,3-61,2 nm sedangkan menggunakan jeruk nipis manis menghasilkan nanoperak dengan ukuran 107 nm. ${ }^{7}$

Perak nanopartikel dapat diaplikasikan ke kulit salah satunya melalui sediaan masker peel-off. Sediaan masker peel-off dipilih sebab mudah diaplikasikan, tidak meninggalkan residu saat dihilangkan dan memberikan sensasi bersih. Selain itu mampu mengoptimalkan kerja perak nanopartikel sebagai antimikroba ketika polimer membentuk lapisan oklusif di permukaan stratum korneum kulit menurut hasil penelitian. ${ }^{8}$

Humektan merupakan bagian penting dalam formula masker peel-off. Humektan dalam sediaan masker peel-off memiliki dua fungsi yakni berkontribusi dalam hidrasi kulit dengan cara menarik air dari lapisan lebih dalam epidermis dan dermis menuju lapisan terluar kulit serta mencegah evaporasi air pada saat penyimpanan sehingga sediaan masker peel-off menjadi lebih stabil dari segi viskositas. Selain itu humektan melengkapi fungsi dari polivinil alcohol, dimana PVA dapat membentuk lapisan film yang lembut dan kuat pada keadaan lembab. ${ }^{9}$ PEG 400 dan gliserin merupakan bahan yang dapat berfungsi sebagai humektan dengan fungsi yang sama namun memiliki sifat berbeda. PEG 400 dan gliserin selain sebagai humektan, kedua bahan ini dapat berfungsi sebagai pelembab yang pada masker dibutuhkan dengan dengan konsentrasi $0,01 \%-20 \%{ }^{10}$ Sifat dari kedua bahan yang mempengaruhi sifat sediaan masker peel-off yakni viskositas dan water-binding capacity. Viskositas bahan akan mempengaruhi viskositas sediaan. Kombinasi humektan diharapkan dapat mengoptimalkan kerja perak nanopartikel dan menghasilkan sediaan peel-off mask yang memenuhi syarat sediaan gel yang baik sesuai SNI No. 06-2588-1992.

\section{Materials and methods}

2.1. Alat

Alat-alat yang digunakan dalam penelitian ini mortar, stamper, hot plate, termometer, cawan porselin, $\mathrm{pH}$ meter (PH-009(I)A: China), timbangan analitik (Mettler Toledo AL204, d $=0,0001 \mathrm{~g}$, Colombus: Ohio), timbangan digital (Precisa 
XB620C, d=0,01g, Moosmattstrasse: Swiss), Spektrofotometer UV-Vis (GenesysTM, Thermo Fisher Scientific: USA), pot, sentrifugator (Mini Spin Plus, Eppendorf AG: Jerman), sendok tanduk, viscometer (Viskotester VT-04, Kokubunji: Jepang), cawan patri, dan inkubator (Memmert IN30, Mammert: Jerman), Particle Size Analyzer (PSA) (HORIBA: USA), Scanning Electron Microscope (SEM)(FEI Quanta 200: USA), serta alat-alat gelas (Pyrex, Singapura).

\subsection{Bahan}

Bahan-bahan yang digunakan dalam penelitian ini $\mathrm{AgNO}_{3} \quad 99,8 \%$ (Merck, Darmstadt, Jerman), kulit jeruk manis $(C$. sinensis), PVA (Kurray Asia Pacific PTE LTD, Singapura), PEG 400 (PT. DOW Chemical, Indonesia), Gliserin (P\&G Chemical, Singapura), Phenoxyethanol, akuades dan akuabides (dikemas ulang oleh CV Agung Jaya, Solo).

\subsection{Pembuatan Perak Nanopartikel}

2.3.1.Penyiapan Rebusan Kulit Jeruk

Kulit jeruk segar diambil kemudian dicuci dan dipotong menjadi bagian lebih kecil. Diambil 4,0 g kulit lalu ditambah akuabides $40 \mathrm{~mL}$ kemudian direbus selama dua menit. Rebusan disaring menggunakan kertas Whatman No. 1. ${ }^{11}$

\subsubsection{Proses Biosintesis Perak}

Larutan $\mathrm{AgNO}_{3}$ 1,0 $\mathrm{mM}$ disiapkan. Tambahkan rebusan kulit jeruk sebanyak $3,0 \mathrm{~mL}$ pada $40 \mathrm{~mL}$ larutan $\mathrm{AgNO}_{3} 1,0 \mathrm{mM}$, selanjutnya dipanaskan diatas waterbath pada suhu $60{ }^{\circ} \mathrm{C}$ selama 45 menit. Terbentuknya koloid perak nanopartikel ditandai dengan perubahan warna dari tak berwarna menjadi coklat kekuningan. ${ }^{11}$

\subsection{Karakterisasi Perak Nanopartikel Hasil Biosintesis}

\subsubsection{Analisa Spektroformetri UV-VIS}

Karakterisasi ukuran nanopartikel perak dilakukan dengan instrumen spektrofotometer UV-Vis. Larutan hasil biosintesis dilakukan pembacaan absorbansi pada rentang SPR (Surface Plasmon Resonance) perak nanopartikel yaitu 350-540 nm, dengan akuades sebagai blanko.

\subsubsection{Particle Size Analysis}

Sejumlah 1,0 $\mathrm{mL}$ larutan perak nanopartikel hasil biosintesis dilakukan pembacaan menggunakan alat Particle Size Analyzer. PSA digunakan untuk mengetahui distribusi ukuran partikel dari partikel sampel.

\subsubsection{Scanning Electron Microscope}

SEMdigunakanuntukmelihatmorfologi dari nanopartikel yang terbentuk. Analisis SEM sampel yang dibutuhkan berupa serbuk. Serbuk perak nanopartikel didapatkan dengan cara koloid perak nanopartikel yang selesai dilakukan proses biosintesis, disentrifugasi pada putaran $10.000 \mathrm{rpm}$ selama 15 menit. Pellet akan mengendap pada bagian bawah effendorf lalu pellet dipindahkan pada cawan petri. Cawan petri berisi pellet dipanaskan pada oven pada suhu $60{ }^{\circ} \mathrm{C}$ selama $24 \mathrm{jam}$. Perak nanopartikel yang kering diambil lalu ditambahkan pellet $\mathrm{KBr}$ dan dilakukan pembacaan menggunakan alat SEM yang dilengkapi dengan carbon coating. ${ }^{12}$

\subsection{Formulasi Masker Peel-off}

Sediaan basis masker dibuat dalam lima formula dengan variasi konsentrasi gliserin dan PEG 400. Rentang konsentrasi gliserin dan PEG 400 berperan sebagai humektan dalam masker peel-off yaitu $0,01 \%-20 \%$. Formula yang dibuat merupakan modifikasi dari sediaan masker peel-off Badnore et al. (2019). ${ }^{13}$ Formula dibuat ditampilkan pada tabel 1. Basis masker dibuat dengan cara akuades dipanaskan terlebih dahulu hingga suhu $80^{\circ} \mathrm{C}$. Polivinil alkohol (PVA) dimasukan secara bertahap keakuades yang telah dipanaskan, lalu diaduk hingga melebur dan homogen (campuran 1). Perbandingan akuades dan PVA yang digunakan yaitu (4:1). PVA dipindahkan ke mortar dan ditambah kombinasi Gliserin-PEG 400 sesuai perbandingan masing-masing formula. Sisa akuades, ditambahkan ke campuran 1, terakhir koloid perak nanopartikel dan parfum ditambahkan lalu diaduk hingga homogen. Pindahkan sediaan pada wadah gelap tertutup. 
Tabel 1. Formula Masker peel off perak nanopartikel hasil biosintesis dengan variasi humektan

\begin{tabular}{cccccc}
\hline \multirow{2}{*}{ Bahan } & \multicolumn{3}{c}{ Bobot (gram) } \\
& F1 & F2 & F3 & F4 & F5 \\
\hline Perak nanopartikel & 27,8 & 27,8 & 27,8 & 27,8 & 27,8 \\
Gliserin & - & 0,12 & 0,25 & 0,38 & 0,5 \\
PEG 400 & 0,5 & 0,38 & 0,25 & 0,12 & - \\
PVA & 13,0 & 13,0 & 13,0 & 13,0 & 13,0 \\
Phenoxyethanol & 0,1 & 0,1 & 0,1 & 0,1 & 0,1 \\
Parfum & qs & qs & qs & qs & qs \\
Akuades & 58,6 & 58,6 & 58,6 & 58,6 & 58,6 \\
\hline
\end{tabular}

2.6. Uji Sifat Fisika dan Kimia Sediaan

2.6.1 Uji Organoleptis

Pengamatan terhadap sediaan yang meliputi konsistensi, warna dan aroma menggunakan panca indra.

\subsubsection{Uji Viskositas}

Viskositas diukur dengan alat Viscometer Rion dengan spindel nomor 2. Cup diisi sediaan masker, selanjutnya rotor ditempatkan pada bagian tengah cup. Alat dinyalakan, tunggu 1 menit kemudian catat viskositas sediaan masker. ${ }^{14}$ Viskositas yang baik dari sediaan masker yakni 300-5000 dPas sesuai SNI No. 06-2588-1992. ${ }^{15}$

\subsubsection{Uji Waktu Kering}

Sediaan masker diambil sejumlah 1,0 gram sediaan masker peel-off, kemudian oleskan pada kulit lebar dengan ukuran $7 \mathrm{x} 7$ $\mathrm{cm}$. Waktu yang dibutuhkan masker untuk membentuk film diukur menggunakan menggunakan stopwatch. Waktu kering yang baik untuk sediaan masker peel-off yakni 1530 menit berdasarkan SNI No. 06-2588-1992. 16

\subsubsection{Pengujian $\mathrm{pH}$ sediaan}

$\mathrm{pH}$ meter dikalibrasi menggunakan buffer $\mathrm{pH}$ 4,01 dan $\mathrm{pH}$ 6,86. Elektroda dimasukan sediaan masker, lalu diaduk hingga menunjukan angka $\mathrm{pH}$ konstan. kemudian amati dan catat $\mathrm{pH}$. Masker yang baik memiliki pH sesuai kulit yakni 4,5-6,5 sesuai SNI No. 06-2588-1992. ${ }^{17}$

Masker peel-off disimpan pada suhu ruang tanpa paparan sinar matahari (20- $25^{\circ} \mathrm{C}$ ). Sifat fisik sediaan diuji pada pada minggu pertama, kedua, ketiga dan keempat. Replikasi dilakukan sebanyak tiga kali.

\subsection{Analisa Data}

Data yang telah diperoleh dari uji sifat fisik dan kimia dianalisis secara statistik menggunakan IBM SPSS Statistic 22. Data dianalisis menggunakan Saphiro Wilk untuk mengetahui distribusi data. Jika data terdistribusi normal maka dilanjutkan uji OneWay ANOVA dengan taraf kepercayaan 95\%, kemudian dilanjut dengan uji LSD (Least Significant Difference) (data yang homogen) dan uji Games-Howell (data tidak homogen) untuk mengetahui perbedaan signifikansinya. Data tidak terdistribusi normal diuji secara non-parametrik menggunakan KruskalWallis $\mathrm{H}$, jika nilai signifikansi $\mathrm{p}<0,05$ maka dilanjutkan uji Mann Whitney siknifikansi antar kelompok.

\section{Result}

Hasil biosintesis menunjukan bahwa rebusan kulit jeruk manis mampu menghasilkan perak nanopartikel dengan karakteristik perubahan warna pada proses biosintesis coklat kekuningan, absorbansi maksimum pada rentang 421-423 nm, berbentuk batang dan rata-rata ukuran partikel $83,17 \pm 7,19 \mathrm{~nm}$ dengan Polidispers Indeks $0,224 \pm 0,103$.

Spektra UV-VIS digunakan untuk memonitoring peristiwa reduksi dari ion perak $(\mathrm{Ag}+)$ menjadi nanoperak $\left(\mathrm{Ag}^{\circ}\right)$ pembacaan sampel tidak lebih dari $1 \times 24$ 


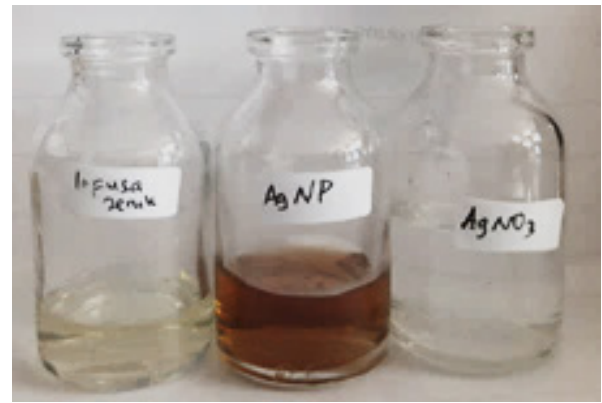

Gambar 1. Hasil visual proses biosintesis perak nanopartikel menggunakan infusa kulit jeruk manis.

jam setelah selesai proses biosintesis. Hasil biosintesis perak nanopartikel menggunakan infusa kulit jeruk manis dapat dilihat pada Gambar 1, spektra absorbansi dapat dilihat pada Gambar 2 serta hasil karakterisasi morfologi SEM dapat dilihat pada Gambar 5. ${ }^{18}$ Hasil uji organoleptis menunjukan bahwa tiap formula memiliki konsistensi yang berbeda, berwarna coklat kekuningan bening dan odorless. Selama penyimpanan empat minggu tiap formula mengalami perubahan warna yang berbeda signifikan dimana warna sediaan berubah menjadi lebih gelap. Hal ini dikarenakan semakin lama proses biosintesis tetap berlangsung sehingga menyebabkan warna semakin gelap.

Hasil uji viskositas menunjukan sediaan memiliki viskositas dengan rentang $995 \pm 5,77$ dPas $-1100 \pm 10$ dPas dimana F1, F2 dan F4 memiliki viskositas tidak berbeda signifikan $(p>0,05)$ serta F3 dan F5 memiliki viskositas tidak berbeda signifikan $(p>0,05)$. F3 memiliki nilai viskositas paling kecil. Sediaan yang beredar di pasaran brand Wardah ${ }^{\circledR}$ memiliki viskositas yang tidak berbeda signifikan $(p>0,05)$ dengan kelima sediaan masker peel-off yang telah dibuat pada penelitian ini. Formula 2 dan formula 4 merupakan sediaan yang tidak mengalami perubahan viskositas selama penyimpanan empat minggu $(\mathrm{p}>0,05)$.

Waktu kering sediaan masker peel-off yang dibuat kurang dari 30 menit. F1 dan F2 memiliki waktu kering tercepat kemudian dilanjutkan dengan F4 dan F5, sedangkan F3 merupakan masker peel-off dengan waktu kering paling lama. Kelima formula mengalami perubahan waktu kering selama penyimpanan empat minggu dimana semua formula mengalami peningkatan waktu kering menjadi lebih lama, kecuali F3. Hasil uji viskositas dan waktu kering dari sediaan masker peel-off ditampilkan pada gambar 3 dan 4.

Hasil uji pH menunjukan kelima formula memiliki nilai $\mathrm{pH}$ menyerupai $\mathrm{pH}$ kulit yakni 4,5-6,5. Perbedaan konsentrasi Gliserin dan PEG 400 tidak mempengaruhi nilai $\mathrm{pH}$ sediaan dan kelima sediaan masker peel-off tidak mengalami perubahan $\mathrm{pH}$ yang signifikan selama penyimpanan empat minggu $(p>0,05)$ pada suhu ruang.

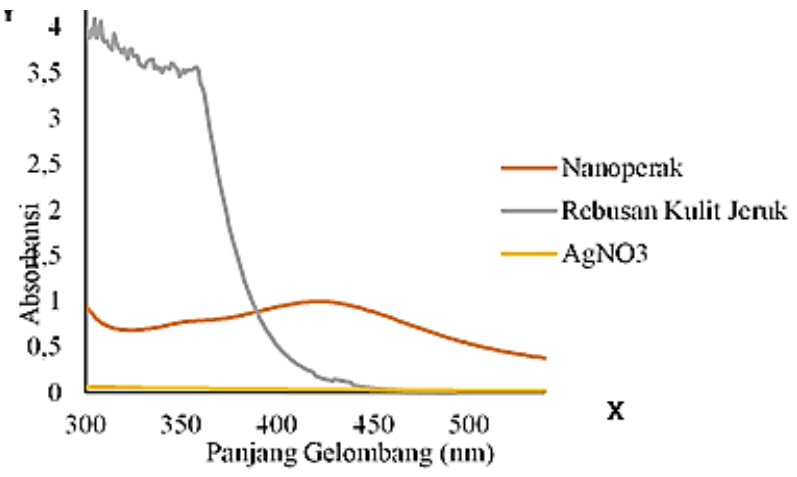

Gambar 2. Hasil absorbansi larutan perak nanopartikel hasil biosintesis pada rentang SPR nanopartikel $350-540 \mathrm{~nm}$ 


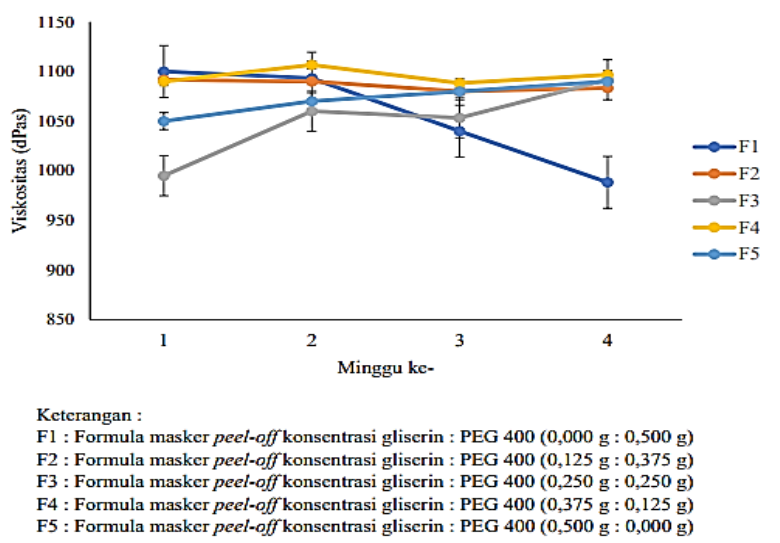

Gambar 3. Hasil uji viskositas sediaan peel-off mask perak nanopartikel

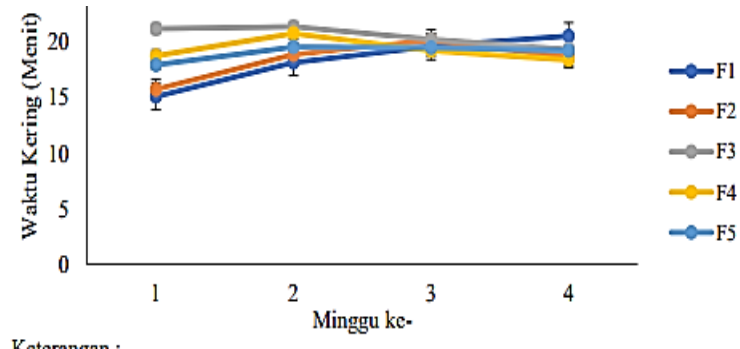

Keterangan :

F1 : Formula masker peel-off konsentrasi gliserin : PEG $400(0,000 \mathrm{~g}$ : $0,500 \mathrm{~g})$

F2 : Formula masker peel-off konsentrasi gliserin : PEG $400(0,125 \mathrm{~g}: 0,375 \mathrm{~g})$

F3 : Formula masker peel-off konsentrasi gliserin : PEG $400(0,250 \mathrm{~g}: 0,250 \mathrm{~g})$

F4 : Formula masker peel-off konsentrasi gliserin : PEG $400(0,375 \mathrm{~g}: 0,125 \mathrm{~g})$

F5 : Formula masker peel-off konsentrasi gliserin : PEG $400(0,500 \mathrm{~g}: 0,000 \mathrm{~g})$

Gambar 4. Hasil uji waktu kering sediaan peel-off mask perak nanopartikel

\section{Discussion}

Biosintesisperaknanopartikeldilakukan dengan cara mereaksikan antara larutan perak nitrat $\left(\mathrm{AgNO}_{3}\right)$ dengan rebusan kulit jeruk manis. Senyawa yang diduga berperan dalam proses biosintesis yaitu senyawa asam sitrat dan flavonoid karena kedua senyawa ini memiliki gugus karbonil dan hidroksil serta tinggi kandungannya pada kulit jeruk $C$. sinensis. ${ }^{1119}$ Biosintesis perak nanopartikel dari larutan $\mathrm{AgNO}_{3}$ 1,0 mM dengan bantuan rebusan kulit jeruk dapat terjadi melalui reaksi reduksi yang melibatkan transfer elektron. Reaksi reduksi ialah suatu reaksi yang menyebabkan sebuah senyawa atau substansi menerima suatu elektron sehingga terjadi reduksi (penurunan) muatan pada atom substansi tersebut. ${ }^{21}$ Proses biosintesis dilakukan pada suhu $60^{\circ} \mathrm{C}$, reaksinya lebih cepat selesai dan ukuran partikel yang dihasilkan lebih kecil dibandingkan proses biosintesis yang dilakukan pada suhu ruang. ${ }^{11}$ Keberhasilan terbentuknya nanopartikel perak hasil biosintesis menggunakan kulit jeruk manis ditandai adanya perubahan warna menjadi coklat kekuningan sehingga pada penelitian ini menunjukan bahwa koloid perak nanopartikel berhasil terbentuk. Spektrofotometri UV-VIS merupakan

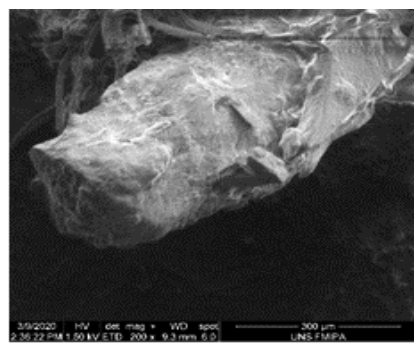

(a)

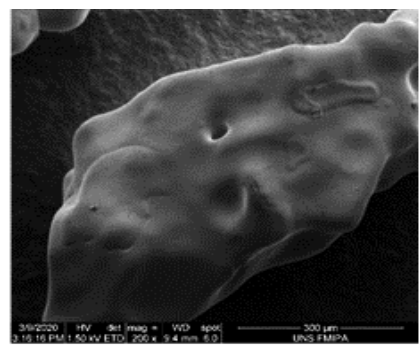

(b)

Gambar 4. Hasil SEM perak nanopartikel hasil biosintesis (a) dan serbuk perak nitrat (b). 
metode yang digunakan untuk melihat optical properties dari perak nanopartikel. ${ }^{20}$ Optical properties tersebut berupa adanya absorbansi maksimal pada daerah SPR yakni $350-450 \mathrm{~nm}^{22}$ Perak nanopartikel memiliki serapan maksimal 421-423 nm sehingga hal ini menunjukan perak nanopartikel berhasil terbentuk pada penelitian ini. Hasil yang ditunjukkan dari hasil PSA bahwa perak nanopartikel memiliki ukuran partikel ratarata $83,17 \pm 7,19 \mathrm{~nm}$. Perak nanopartikel hasil biosintesis dari penelitian Kaviya et al (2011) memiliki ukuran partikel rata-rata $10 \pm 1 \mathrm{~nm}$. Perbedaan ukuran ini mungkin disebabkan oleh perbedaan kadar agen pereduksi pada kulit jeruk manis yakni asam sitrat dan flavonoid. Perbedaan kandungan senyawa ini dipengaruhi oleh perbedaan geografis, lamanya paparan sinar matahari, temperatur lingkungan. ${ }^{23}$

Hasil karakterisasi morfologi menunjukan perbedaan signifikan antara perak nanopartikel hasil biosintesis dengan serbuk perak nitrat pada permukaannya. Pada Gambar 5 permukaan perak nitrat sangat halus dan tidak terdapat partikel yang melapisinya, namun setelah dibiosintesis terlihat adanya material biologi atau senyawa yang melapisi bagian permukaan perak nanopartikel yang terbentuk yang diduga material biologi tersebut berasal dari rebusan kulit jeruk yang berfungsi sebagai capping agent. ${ }^{24}$

Masker Peel-off yang dibuat pada penelitian ini terdiri dari 5 formula dengan replikasi 3 kali pada tiap formulanya. Tiap formula memiliki variasi konsentrasi Gliserin dan PEG 400 dengan jumlah bahan keduanya yaitu 0,5 gram. Kedua bahan tersebut memiliki fungsi sebagai humektan yang berperan dalam menjaga viskositas sediaan dengan cara mencegah evaporasi air dan menyerap air dari lingkungan. Kedua humektan ini dikombinasikan sebab memiliki fungsi yang sama namun karakteristik yang berbeda dimana gliserin memiliki viskositas dan kemampuan menyerap air lebih besar dibandingkan PEG 400. PVA pada penelitian ini berperan sebagai film forming agent. PVA memiliki kelebihan yakni film yang dihasillkan memiliki sifat adhesif yang baik sehingga memberikan sensasi rasa bersih, selain itu film yang dihasilkan bersifat ramah lingkungan dan non toksik. ${ }^{25}$ PVA memiliki interaksi terhadap Gliserin dan PEG 400, salah satu faktor yang mempengaruhinya kemampuan membentuk film dari PVA yaitu kelembaban. Pada kelembapan yang rendah, PVA akan membentuk suatu film yang keras dan rapuh, ketika kelembaban ditingkatkan maka sifat fisik film yang terbentuk yaitu lunak dan fleksibel. Perak nanopartikel berperan sebagai zat aktif. Phenoxyethanol berfungsi sebagai pengawet. Parfum berfungsi sebagai odoris agent.

Kelima formula memiliki warna coklat kekuningan bening. Warna ini berasal dari zat aktif perak nanopartikel yang dibiosintesis dengan rebusan kulit jeruk. Salah satu keunggulan menggunakan perak nanopartikel sebagai zat aktif dalam suatu sediaan yaitu dapat meningkatkan penampilan dari sediaan sehingga lebih menarik salah satunya warna yang dihasilkan lebih transparan sehingga pada penelitian ini telah menghasilkan sediaan yang diharapkan yaitu menghasilkan sediaan yang bening. ${ }^{5}$ Semua formula menghasilkan aroma yang khas yang yang relatif sama berasal dari parfum yang digunakan. Perubahan warna yang signifikan pada tiap formula selama penyimpanan empat minggu disebabkan oleh interaksi zat aktif perak nanopartikel dengan komponen penyusun formula sediaan. Gliserin, PEG 400 dan PVA memiliki kemampuan untuk mereduksi perak sehingga membentuk menstabilkan perak nanopartikel. ${ }^{26 ; 27 ; 28}$ Ketiga komponen tersebut memiliki gugus hidroksil yang mampu berinteraksi dengan ion perak sehingga ion perak tereduksi. Perubahan warna pada sediaan kemungkinan diakibatkan proses lanjutan reaksi reduksi sehingga proses sintesis perak nanopartikel masih terjadi ketika koloid nanopartikel perak dimasukan dalam sediaan masker dengan formula tersebut.

Perbedaan konsentrasi gliserinPEG 400 mempengaruhi nilai viskositas sediaan. F1 memiliki viskositas yang lebih besar dibandingkan F5, hal ini menunjukan penambahan PEG 400 pada sediaan memberikan viskositas yang lebih besar 
dibandingkan menggunakan Gliserin. Hal ini dapat dikaitkan dengan kemampuan masing-masing bahan dalam menyerap air. Kemampuan menyerap air pada humektan dipengaruhi oleh gugus - $\mathrm{OH}$ yang dimiliki, dimana semakin banyak gugus - $\mathrm{OH}$ pada humektan akan meningkatkan kemampuan penyerapan air. Gliserin memiliki gugus -OH lebih banyak dibandingan PEG 400 sehingga Gliserin dapat mengikat air lebih banyak dari lingkungan sehingga viskositas pada F5 lebih kecil dibandingkan F1. Gliserin dan PEG 400 ketika dikombinasikan dengan komposisi 50:50 kemampuan higroskopisitasnya meningkat secara signifikan yang ditunjukan oleh viskositas F3 paling kecil dibandingkan keempat formula lainnya. Komposisi Gliserin dan PEG 400 mempengaruhi perubahan viskositas sediaan masker peel-off selama penyimpanan empat minggu. Penurunan viskositas secara berkelanjutan pada F1 disebabkan oleh kadar PEG 400 yang tinggi. PEG 400 merupakan suatu polimer yang memiliki karakteristik yang khas. PEG 400 memiliki kemampuan mengikat air dipengaruhi oleh gugus hidroksilnya, selain itu karakteristik khas PEG yaitu memiliki kinematik viskositas. Karakter khas ini diperoleh dari rantai polimer PEG 400 yang panjang dimana rantai tersebut memiliki kemampuan melipat-lipat sehingga terbentuk suatu segmen-segmen pada PEG 400 yang dapat membentuk ikatan hidrogen dengan air sehingga kandungan air dalam sediaan semakin meningkat. F5 mengalami peningkatan viskositas secara berkelanjutan yang kemungkinan disebabkan oleh PVA. PVA pada saat proses formulasi, dilakukan pemanasan. Hal ini menyebabkan ikatan hidrogen intra maupun inter molekul menjadi putus sehingga kelarutan PVA meningkat dan viskositasnya menurun, setelah proses pemanasan selesai, terjadi penurunan suhu, hal ini menyebabkan ikatan-ikatan hidrogen yang awalnya terputus, akan terbentuk kembali secara bertahap sehingga viskositas sediaan meningkat. Gliserin dan PEG 400 0,38:0,12 g maupun sebaliknya merupakan komposisi optimal. Hal ini ditunjukan oleh F2 dan F4 memiliki viskositas yang stabil selama penyimpanan empat minggu. Kemampuan menyerap air dari Gliserin dan PEG 400 mampu mengimbangi fenomena ikatan hidrogen pada PVA sehingga viskositas tidak berubah secara signifikan tiap minggunya.

Komposisi Gliserin dan PEG 400 juga mempengaruhi waktu kering sediaan masker peel-off perak nanopartikel. Sediaan dengan adanya komposisi PEG 400 lebih besar (F1 dan F2) memiliki waktu kering yang lebih cepat dibandingkan dengan sediaan dengan komposisi gliserin lebih besar hal ini disebabkan oleh kemampuan dalam menarik air komponen ke sediaan masker peel-off. Pada minggu pertama Gliserin memiliki kemampuan menarik air ke sediaan lebih besar dibandingkan PEG 400 sehingga kandungan air dalam sediaan lebih besar sehingga akan meningkatkan waktu kering sediaan masker peel-off. ${ }^{29} \mathrm{~F} 3$ memiliki waktu kering yang paling lama karena kemungkinan dengan komposisi Gliserin-PEG 400 (0,25:0,25 g) mampu memberikan efek sinergis dalam menarik air dari lingkungan sehingga kandungan air pada sediaan F3 lebih banyak daripada keempat formula lainnya. Semua formula mengalami peningkatan waktu kering selama penyimpanan empat minggu kecuali F3. Hal ini disebabkan Gliserin dan PEG 400 memiliki sifat higroskopis dimana terjadi mekanisme penyerapan air dari lingkungan sekitar. Adanya peningkatan air pada sediaan dapat mempengaruhi waktu kering. Pada F3 aktivitas PVA dalam meningkatkan viskositas sediaan lebih besar dibandingkan dengan kemampuan penyerapan air oleh kombinasi humektan. Dapat disimpulkan kombinasi Gliserin-PEG 400 dengan perbandingan 25: $25 \%$ berdampak pada penurunan waktu kering. Selain kandungan air, waktu kering juga dipengaruhi oleh viskositas dimana semakin tinggi viskositas maka waktu kering akan semakin berkurang. ${ }^{30}$

\section{Conclussion}

Perak nanopartikel yang dihasilkan dari proses biosintesis menggunakan rebusan kulit jeruk manis memliki karakteristik perubahan warna menjadi coklat kekuningan, absorbansi maksimum pada rentang 421-423 
$\mathrm{nm}$, berbentuk batang dan rata-rata ukuran partikel 83,17 $\pm 7,19 \mathrm{~nm}$ dengan Polidispers Indeks $0,224 \pm 0,103$. Perbedaan konsentrasi Gliserin dan PEG 400 pada formula masker peel-off memberikan pengaruh signifikan terhadap sifat fisik sediaan yang meliputi viskositas dan waktu kering, namun tidak mempengaruhi sifat kimia yaitu $\mathrm{pH}$ masker peel-off. Komposisi Gliserin dan PEG 400 dengan perbandingan 25: $75 \%$ dan 75 : $25 \%$ memiliki viskositas, waktu kering dan $\mathrm{pH}$ yang tidak berbeda signifikan selama penyimpanan empat minggu pada suhu ruang.

\section{References}

1. Dreno, B., Martin, R., Moyal, D., Henley, J.B., Khammari, A., Seité, S. 2017. Skin Microbiome and Acne vulgaris: Staphylococcus, a New Actor in Acne. Experimental Dermatology, 26: 798-803.

2. Fox, L., Csongradi, C., Aucamp, M., Du Plessis, J., Gerber, M. 2016. molecules Treatment Modalities for Acne. Molecules, 27: 1-20.

3. Ahmed, S., Ahmad, M., Swami, B.L., Ikram, S. 2016. A Review on Plants Extract Mediated Synthesis of Silver Nanoparticles for Antimicrobial Applications: A Green Expertise. Journal of Advanced Research, 7: 17-28.

4. Sakharwade, S. 2016. Silver Nanoparticles in Cosmetics. Journal of Cosmetics, Dermatological Sciences and Applications, 6: 48-53.

5. Pulit-Prociak, J., Grabowska, A., Chwastowski, J., Majka, T.M., Banach, M. 2019. Safety of the Application of Nanosilver and Nanogold in Topical Cosmetic Preparations. Colloids and Surfaces B: Biointerfaces, 18: 110416.

6. Campbell, C.S.J., Contreras-Rojas, L.R., Delgado-Charro, M.B., Guy, R.H. 2012. Objective Assessment of Nanoparticle Disposition in Mammalian Skin After Topical Exposure. Journal of Controlled Release, 162: 201-207.

7. Nisha, S.Najimu., Aysha,Q.S., Rahman, SN., Kumar, RV. 2014. Lemon Peels Mediated Synthesis of Silver Nanoparticles and its Antidermatophytic
Activity. Spectrochimica Acta Part A Molecular and Biomolecular Spectroscopy, 124C: 194-198

8. Velasco., D Pohl1., A Surrey., A BonattoMinella., A Hernando., P Crespo., Rellinghaus.2012. On the stability of AuFe alloy nanoparticles. Nanotechnology, 25: 215703

9. Ogur, E., 2005. Polyvinyl Alcohol: Materials, Processing and Applications, Rapra Tecnology. UK.

10. Liew, S.S., Ho, W.Y., Yeap, S.K., Bin Sharifudin, S.A. 2018. Phytochemical Composition and in Vitro Antioxidant Activities of Citrus sinensis Peel Extracts. PeerJ, 6: 1-16.

11. Kaviya, S., Santhanalakshmi, J., Viswanathan, B., Muthumary, J., Srinivasan, K. 2011. Biosynthesis of Silver Nanoparticles Using Citrus sinensis Peel Extract and its Antibacterial Activity. Spectrochimica Acta - Part A: Molecular and Biomolecular Spectroscopy, 79: 594-598.

12. Kaushik, U., Joshi, S.C. 2015. Silver Nanoparticles: Green Synthesis, Optical Properties, Antimicrobial Activity and Its Mechanism Using Citrus sinensis. innovareacademics.org, 8: 179-184.

13. Badnore, A.U., Sorde, K.I., Datir, K.A., Ananthanarayan, L., Pratap, A.P., Pandit, A.B. 2019. Preparation of Antibacterial Peel-off Facial Mask Formulation Incorporating Biosynthesized Silver Nanoparticles. Applied Nanoscience (Switzerland), 9: 279-287.

14. Puspitasari, A.D., Setyowati, D.A. 2019. Evaluasi Karakteristik Fisika Kimia dan Nilai SPF Sediaan Gel Tabir Surya Ekstrak Etanol Daun Kersen (Muntingia calabura L). Jurnal Pharmascience, 5: 153-162.

15. Pertiwi, R.D., Kristanto, J., Praptiwi, G.A. 2016. Uji Aktivitas Antibakteri Formulasi Gel Untuk Sariawan Dari Ekstrak Daun Saga ( Abrus precatorius Linn.) terhadap Bakteri Staphylococcus aureus. Jurnal Ilmiah Manuntung, 2: 1-9.

16. Cahyani, I.M., Putri, I.D.C. 2018. Formulation of Peel-Off Gel From Extract 
Of Curcuma heyneana Val \& Zijp Using Carbopol 940. Journal of Pharmaceutical and Medicinal Sciences, 2: 48-51.

17. Budiman, A., Aulifa, D.L., Kusuma, A.S.W., Kurniawan, I.S., Sulastri, A. 2017. Peel-off Gel Formulation from Black Mulberries (Morus nigra) Extract as Anti-acne Mask. National Journal of Physiology, Pharmacy and Pharmacology, 7: 987-994.

18. Logeswari, P., Silambarasan, S., Abraham, J. 2012. Synthesis of Silver Nanoparticles Using Plants Extract and Analysis of Their Antimicrobial Property. Journal of Saudi Chemical Society, 19: 311-317.

19. Canan, I., Gundogdu, M., Seday, U., Oluk, C.A., Karasahin, Z., Eroglu, E.C., Yazici, E., Unlu, M. 2016. Determination of Antioxidant, Total Phenolic, Total carotenoid, Lycopene, Ascorbic Acid, and Sugar Contents of Citrus species and Mandarin hybrids. Turkish Journal of Agriculture and Forestry, 40: 894-899.

20. Kotz, J., Treichel, P., Townsend, J. 2010. Chemistry and Chemical Reactivity, Seventh Ed. ed. Thomson Higher Education, USA.

21. Shnoudeh, A.J., Hamad, I., Abdo, R.W., Qadumii, L., Jaber, A.Y., Surchi, H., Alkelany, S.Z. 2019. Synthesis, Characterization and Applications of MetalNanoparticle,in:Tekade, R.K.(Ed.), Biomaterial and Bionanotechnology. Academic Press, pp. 527-612.

22. Logeswari, P., Silambarasan, S., Abraham, J. 2012. Synthesis of Silver Nanoparticles Using Plants Extract and Analysis of Their Antimicrobial Property. Journal of Saudi Chemical Society, 19: 311-317.

23. Ghasemzadeh, A., Jaafar, H.Z.E., Bukhori, M.F.M., Rahmat, M.H., Rahmat, A. 2018. Assessment and Comparison of Phytochemical Constituents and Biological Activities of Bitter bean (Parkia speciosa Hassk.) Collected from Different Locations in Malaysia. Chemistry Central Journal, 12: 1-9.

24. Ibrahim, H.M.M. 2015. Green
Synthesis and Characterization of Silver Nanoparticles Using Banana Peel Extract and Their Antimicrobial Activity Against Representative Microorganisms. Journal of Radiation Research and Applied Sciences, 8: 265-275.

25. Kathe, K., Kathpalia, H. 2017. Film Forming Systems for Topical and Transdermal Drug Delivery. Asian Journal of Pharmaceutical Sciences, 12: 487-497.

26. Mohammed, A.A., Mahmood, S.T. 2018. Easy and New Chemical Synthesis of Stable Nano Sliver using Propylene Glycol and Glycerin as Reducing Agents 36: 131-135.

27. Oliveira, R.N., Quilty, B., Alves, G.G., Soares, G.D.A., Rouze, R., Mcguinness, G.B., Thire, R.M.S.M. 2013. Mechanical Properties and In Vitro Characterization of Polyvinyl Alcohol- Nano-silver Hydrogel Wound Dressings. Interface Fokus, 4: 1-11.

28. Reshma, Raju, S., Veerasomaiah, P. 2018. Synthesis and Characterization of PEGAg Nanoparticles : Investigation of their Antibacterial Properties 11: 7-12.

29. Santoso, I., Prayoga, T., Agustina, I., Rahayu, W.S. 2020. Formulasi Masker Gel Peel-off Perasan Lidah Buaya (Aloe vera L.) dengan Gelling Agent Polivinil Alkohol. Jurnal Riset Kefarmasian Indonesia, 2: 17-25.

30. Mahyun, F., Kusuma, A.., Tamhid, H.A. 2018. Formulation Peel-off gel mask of Impatiens balsamina 1. as an antibactery against Staphylococcus aureus. Indonesian Journal of Medicine and Health, 9: 1552-1565. 